\title{
El uso de tierras comestibles por los pueblos costeros del Periodo de Integración en los Andes septentrionales
}

L'usage de terres comestibles par les populations côtières de la Période

d'Intégration dans les Andes septentrionales

The use of edible earth by coastal peoples of the Integration Period in the

Northern Andes

Mercedes Guinea

\section{OpenEdition}

Journals

Edición electrónica

URL: http://journals.openedition.org/bifea/3882

DOI: $10.4000 /$ bifea.3882

ISSN: 2076-5827

Editor

Institut Français d'Études Andines

Edición impresa

Fecha de publicación: 1 diciembre 2006

Paginación: 321-334

ISSN: 0303-7495

Referencia electrónica

Mercedes Guinea, «El uso de tierras comestibles por los pueblos costeros del Periodo de Integración en los Andes septentrionales », Bulletin de l'Institut français d'études andines [En línea], 35 (3)| 2006, Publicado el 01 junio 2007, consultado el 01 diciembre 2020. URL : http://journals.openedition.org/ bifea/3882 ; DOl : https://doi.org/10.4000/bifea.3882

\section{(c) $(ஒ) \ominus$}

Les contenus du Bulletin de l'Institut français d'études andines sont mis à disposition selon les termes de la licence Creative Commons Attribution - Pas d'Utilisation Commerciale - Pas de Modification 4.0 International. 


\title{
El uso de tierras comestibles por los pueblos costeros del Periodo de Integración en los Andes septentrionales
}

\author{
Mercedes Guinea*
}

\section{Resumen}

Los grupos humanos comparten con algunas especies animales la costumbre de ingerir determinadas tierras como complemento alimenticio, sin embargo, son pocas las evidencias arqueológicas de este consumo. Una peculiar forma de preparación de estos complementos alimenticios ha permitido su preservación y recuperación en los sitios de Atacames y Japotó, en la costa del Ecuador. En este artículo se presentan dichos artefactos y se sugieren hipótesis sobre sus posibles usos.

Palabras clave: arqueología, Ecuador prehispánico, geofagia

L'usage de terres comestibles par les populations côtières de la Période d'Intégration dans les Andes septentrionales

\section{Résumé}

Divers groupes humains partagent avec plusieurs espèces animales la « géophagie » qui consiste à ingérer certaines terres comme un complément alimentaire naturel. Toutefois, les évidences archéologiques en sont rarissimes. Un type particulier de préparation de tels compléments a permis leur conservation et leur découverte sur les sites d'Atacames et de Japoto sur la côte de l'Équateur. Dans cet article sont présentés ces artefacts et plusieurs hypothèses sur leur éventuels usages.

Mots clés : archéologie, Équateur préhispanique, géophagie 


\title{
The use of edible earth by coastal peoples of the Integration Period in the Northern Andes
}

\begin{abstract}
Both human groups and some animal species share the custom of ingesting certain kinds of earth as a dietary complement, nevertheless, there is little archaeological evidence of this practice. The preparation of edible earth resulted in a peculiar kind of artifact that has been preserved and recovered from archaeological sites at Atacames and Japoto in the coast of Ecuador. In this paper these artifacts are described and their possible uses are discussed.
\end{abstract}

Key words: archaeology, prehispanic Ecuador, geophagia

\section{INTRODUCCIÓN}

Hace ya más de 30 años que en las excavaciones realizadas en el yacimiento de Atacames los miembros del Proyecto Esmeraldas, sacamos a la luz una considerable cantidad de unos objetos de tierra arcillosa ligeramente cocida, cuya función y significado no fue posible establecer. Los bautizamos de forma informal como empanadillas y, consagrado este nombre por el tiempo, así me voy a referir a ellos de ahora en adelante (fig. 1). Desde entonces, siempre que he tenido oportunidad, viajes, visitantes, congresos, he mostrado a mis colegas estos artefactos, sin que ninguno me diera noticia de un hallazgo similar en Ecuador o en cualquier otro lugar. Tampoco fueron reconocidos en su día por los trabajadores o nativos allegados, durante el desarrollo del proyecto. Siempre mantuve la curiosidad, pero llegué a aceptar las empanadillas como un objeto idiosincrásico del citado yacimiento. Cuando en 2004 volví a encontrar empanadillas en el montículo J3 de Japoto, mi primera excavación dentro del Proyecto Manabí Central (fig. 2), decidí que era necesario retomar la investigación. Los resultados obtenidos en esta ocasión son más prometedores y creo que fundamentan ampliamente la hipótesis que presentamos más abajo, de que son un preparado de tierras comestibles, es decir una evidencia de geofagia en la región.

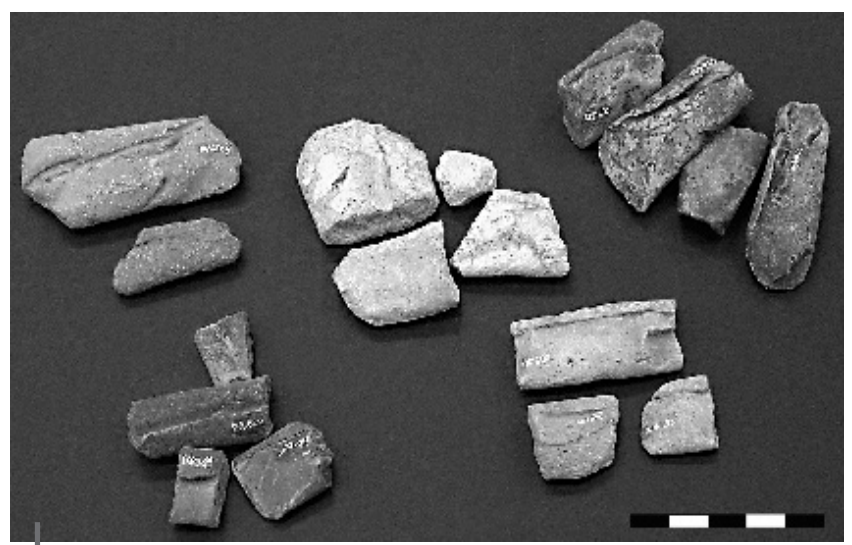

Figura 1- Algunos de los cerca de 500 objetos que se denominaron empanadillas recuperados en las excavaciones del yacimiento Atacames (1974-1975)

Foto: M. Guinea 


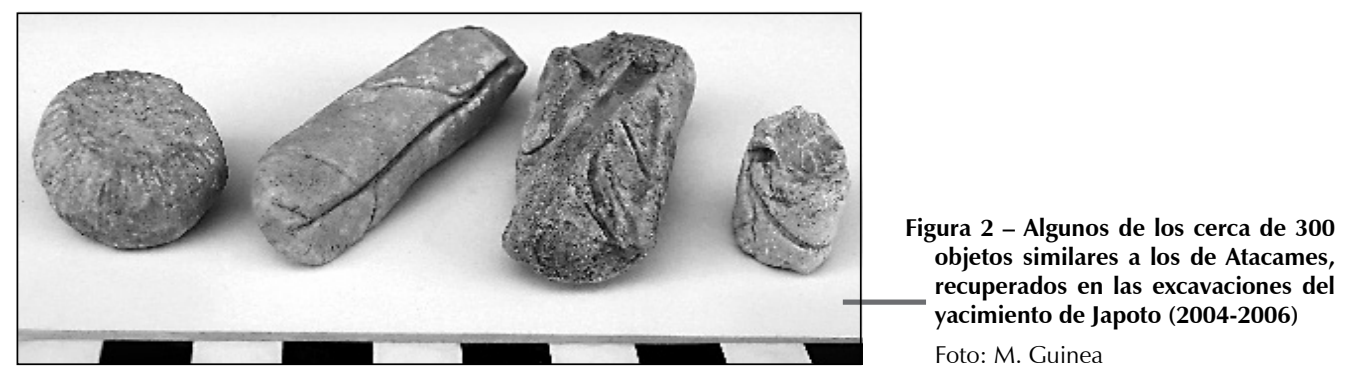

Ciertos grupos humanos comparten con algunas especies animales la costumbre de ingerir determinadas tierras como complemento alimenticio. Se entiende por geofagia el consumo regular y deliberado de materiales terrosos como suelos, arcillas y otras substancias minerales. Si se consumen cantidades anormales, o se convierte en un hábito incontrolable, este comportamiento se considera una de las formas más frecuentes de la pica, la ingesta persistente y compulsiva de sustancias no nutritivas, cuyas variadas causas desde el punto de vista médico van desde un desorden psicológico obsesivo-compulsivo a una enfermedad metabólica. Sin embargo, la constancia de que existe un consumo habitual o circunstancial (embarazo, niñez, enfermedad) de arcillas y tierras desde la época greco-romana que se mantiene en la farmacopea tradicional de grupos indígenas de todos los continentes (Simon, 1998), junto al aprecio que de sus posibles beneficios para la salud hacen las medicinas naturistas de las sociedades modernas, ha llevado a la medicina oficial a investigar cuáles son estos beneficios y los mecanismos fisiológicos implicados. La mayoría de los investigadores en el pasado se decantaron por ver la geofagia como la adquisición de un suplemento de los minerales necesarios para el buen funcionamiento del organismo, en especial del hierro, ya que es frecuente que los consumidores tengan anemia ferropénica (Weis, 1953; Lanzkowsky, 1959). Como no todos los anémicos sienten la necesidad de consumir estas tierras ricas en hierro, otros rebaten esta posición estableciendo que es precisamente el consumo de arcilla lo que inhibe la absorción de este oligoelemento y provoca la anemia (Danford, 1982). Estudios recientes concluyen que la función más plausible de la geofagia humana es mantener la salud gastrointestinal en contextos de explotación de plantas marginales, o con un gran contenido de fitotoxinas, ya que minimiza las diarreas y otros efectos adversos derivadas del consumo de estas plantas, lo que representa una gran ventaja adaptativa (Dominy et al., 2004). Otros opinan que cumplen ambas funciones (Jonhs \& Duquete, 1991; Wilson, 2003). En cualquier caso, el consumo de diferentes tipos de tierras por los indígenas americanos está ampliamente documentado en la literatura etnográfica y sus usos se pueden agrupar en cuatro categorías que con mucha frecuencia se presentan interrelacionadas: medicina, condimento, sustituto alimenticio y objeto ritual. Nos referiremos a esto con más detalle, después de contextualizar y describir los artefactos que nos ocupan.

\section{EL CONTEXTO ARQUEOLÓGICO}

El Periodo de Integración (800-1535 d.C.) se caracteriza por un fuerte incremento de la complejidad sociopolítica en todo el territorio del actual Ecuador, pero muy especialmente en la zona costera, en cuya mayor parte durante este último periodo prehispánico se asentaban extensos poblados pertenecientes a diversas culturas reconocibles arqueológicamente por grandes extensiones de montículos artificiales, conocidos en la región como tolas, la mayor parte de los cuales han sido destruidos por el crecimiento de la poblaciones actuales. Entre estas culturas destaca la Manteña-Huancavilca, que ocupaba buena parte de la costa sur y central, en la que se encuadra el yacimiento de Japoto. Por otra parte, los habitantes de Atacames, aunque más al norte, también quedaban en la órbita de influencia de los Manteños-Huancavilcas ya que debían «cierta sujeción» (Samano, 1844 [1525]: 199) a uno de sus señoríos, Salangone. 


\section{1. Yacimiento de Atacames}

Varios centenares de los artefactos que nos ocupan fueron recuperados en las excavaciones del yacimiento de Atacames dentro de los trabajos del Proyecto Esmeraldas (1971-1975) (Alcina, 1979). Este yacimiento, localizado en la bahía del mismo nombre, en la costa norte de Ecuador, fue el primer poblado que los expedicionarios de Bartolomé Ruiz avistaron en las costas de Sudamérica (Samano, 1844 [1525]: 196-199). Estuvo ocupado desde el período Formativo, y en el momento del contacto con los españoles era un poblado semi-urbano de más de 5000 habitantes, cuya principal ocupación era la pesca y el comercio de Spondylus y otros productos, dentro de la red de intercambio controlada por los Manteño-Huancavilcas, en el límite norte de la influencia directa de estos (Guinea, 1988; 1989; 1993).

La exploración sistemática de la zona por los miembros del Proyecto Esmeraldas reveló un área de ocupación de al menos 127 ha. Desgraciadamente, parte del yacimiento, posiblemente el centro nuclear del mismo, se encontraba debajo del poblado de Atacames, y sus aledaños estaban totalmente destruidos por los cultivos de algodón y otros. A pesar de esto, se localizó un área de unas 50 ha dedicadas a la ganadería, que no había sido demasiado perturbada por las tareas agrícolas y las reocupaciones, en la que se localizaron 65 montículos habitacionales de distintos tamaños y alturas y las huellas de otros muchos, en los que se realizaron diversas campañas de excavación y muestreo (Alcina, 1979; Guinea, 1984). Actualmente debido a la belleza paisajística del lugar y a la mejora de las comunicaciones Atacames se ha convertido en un lugar turístico cuyos complejos hoteleros han destruido totalmente el sitio arqueológico.

\section{2. Japoto}

El yacimiento de Japoto, citado por primera vez por Estrada (1957: 33; 1962: 28) como San Jacinto, es el único sitio con montículos que se ha preservado en la costa de Manabí y es uno de los focos de atención del Proyecto Manabí Central desarrollado desde el año 2003 por la Misión Francesa en Ecuador en colaboración con la Universidad Complutense y el Cantón de Sucre (Bouchard, 2004; 2005).

El yacimiento arqueológico, en las proximidades de la parroquia de San Jacinto, a $28 \mathrm{~km}$ de Bahía de Caráquez, se localiza a $2 \mathrm{~km}$ de la línea de la playa². Los trabajos de prospección han localizado 60 tolas, aunque todavía no se tiene la delimitación precisa del sitio debido a lo impenetrable de la vegetación que lo recubre en parte. La intervención arqueológica durante los veranos de 2004, 2005 y 2006 se ha concentrado en el área NE en el que las tolas visibles, con una altura entre 1 y $5 \mathrm{~m}$, tienen plantas rectangulares, ovaladas o redondas, alcanzando las más grandes hasta $60 \mathrm{~m}$ de largo. Los materiales recuperados están en proceso de análisis, pero los primeros resultados de los estudios cerámicos confirman su pertenencia a la cultura manteña 2 . Hasta el momento solo tenemos una fecha de C14: 1100 d.C. Se ha intervenido con distinta intensidad en 7 montículos recuperándose cerca de trescientos de los artefactos de nuestro interés.

\section{DESCRIPCIÓN DE LOS ARTEFACTOS}

El aspecto de los artefactos que nos ocupan, las empanadillas, es fácilmente reconocido por los actuales ecuatorianos como el de los tamales, bollos, humitas u otros alimentos cotidianos

\footnotetext{
${ }^{1}$ GPS: $9^{\circ} 17^{\prime} 37^{\prime \prime}$ Sur, $80^{\circ} 30^{\prime} 36^{\prime \prime}$ Oeste.

${ }^{2}$ Más información sobre el Proyecto Manabí y sus resultados en la página web: http://macgalatea.sip.ucm.es/web/ infoProyecto/manabicentral.php
} 
que se envuelven en hojas para su cocinado. Especialmente los dulces, que son de tamaño más reducido. Son básicamente distintas tierras que fueron envueltas en hojas, y sometidas después a una ligera cocción u horneado. La cocción las endureció, mientras que la hoja produjo una impresión que aún se conserva (figs.1 y 2). Esta ligera cocción es la que ha permitido su conservación a través del tiempo, y su forma y la impresión de la hoja lo que permite identificarlas en los trabajos de excavación. Aunque es fácilmente reconocible que los hallazgos de Japoto y Atacames pertenecen a la misma clase de artefactos, presentan algunas diferencias en su aspecto y en el análisis de su composición. Vamos a detallarlos por separado.

\section{1. Tipología formal de las empanadillas de Atacames}

En las dos temporadas de excavaciones del sitio de Atacames se recuperaron 20 empanadillas enteras, 315 incompletas y 150 fragmentos, sumando un total de 485 ejemplares. Todas fueron envueltas en una hoja, con el raquis en la dirección del lado más largo, y presionadas en los extremos hacia abajo (si fueron atadas, no se conserva la impresión de la tira), lo que les da una forma característica, rectangular y aplastada. Tienen una gran uniformidad formal, que hemos denominado tipo Tamal, dentro del cual se pueden distinguir cuatro subtipos (fig. 3, tabla 1) en función del tamaño y longitud:

- Tamal Grande, con solo 6 fragmentos recuperados (fig. 3d)

- Tamal Común (largo entre 7 y 5,5 cm), el más frecuente (fig. 3b)

- Tamal Largo (largo entre 9 y $8 \mathrm{~cm}$ ) (fig. 3a)

- Tamal Corto (largo entre 4,8 y 3,3 cm (fig. 3c)

Tabla 1 - Valores estadísticos de las medidas de ancho, grueso y largo de los tipos y subtipos establecidos para las empanadillas de Atacames y Japoto

\begin{tabular}{|c|c|c|c|c|c|c|c|c|c|}
\hline \multirow{2}{*}{\multicolumn{2}{|c|}{$\begin{array}{c}\text { ATACAMES } \\
\underset{(465 \text { ejemplares) }}{n^{\circ}}\end{array}$}} & \multirow[b]{2}{*}{$\%$} & \multicolumn{3}{|c|}{$\begin{array}{c}\text { LARGO } \\
(\mathrm{cm})\end{array}$} & \multicolumn{2}{|c|}{$\begin{array}{l}\text { ANCHO } \\
(\mathrm{cm})\end{array}$} & \multicolumn{2}{|c|}{$\begin{array}{l}\text { GROSOR } \\
(\mathrm{cm})\end{array}$} \\
\hline & & & $\mathrm{m}$ & std & rango & $\mathrm{m}$ & std & $\mathrm{m}$ & std \\
\hline Tipo Tamal & 465 & 100 & & & & & & & \\
\hline Incompletas & 315 & & - & - & - & 2,1 & 0,3 & 1,0 & 0,2 \\
\hline Subt. Corto & 9 & & 4,1 & 0,5 & $3,3-4,8$ & 2,1 & 0,2 & 1,0 & 0,2 \\
\hline Subt. Común & 9 & & 6,5 & 0,4 & $5,5-7$ & 2,2 & 0,2 & 1,1 & 0,2 \\
\hline Subt. Largo & 2 & & 8,5 & 0,5 & $8-9$ & 2,1 & 0,4 & 1,0 & 0,2 \\
\hline Subt. Grande & 6 & & 12,0 & - & & 6,0 & - & 3,0 & - \\
\hline
\end{tabular}

\begin{tabular}{|c|c|c|c|c|c|c|c|c|c|}
\hline \multirow{2}{*}{\multicolumn{2}{|c|}{$\begin{array}{c}\text { JAPOTO } \\
(302 \text { ejemplares) } \\
\mathrm{n}^{\mathbf{0}}\end{array}$}} & \multirow[b]{2}{*}{$\%$} & \multicolumn{3}{|c|}{$\begin{array}{c}\text { LARGO } \\
(\mathrm{cm})\end{array}$} & \multicolumn{2}{|c|}{$\begin{array}{c}\text { ANCHO } \\
(\mathrm{cm})\end{array}$} & \multicolumn{2}{|c|}{$\begin{array}{c}\text { GROSOR } \\
(\mathrm{cm})\end{array}$} \\
\hline & & & $\mathrm{m}$ & std & rango & $\mathrm{m}$ & std & & \\
\hline Tipo Tamal & 113 & 37 & & & & & & & \\
\hline Subt. Común & 72 & 63 & - & - & - & 2,1 & 0,2 & 1,5 & 0,2 \\
\hline Subt. Largo & 39 & 34 & - & - & - & 1,7 & 0,1 & 1,3 & 0,1 \\
\hline Subt. Grande & 2 & 2 & 12,0 & - & - & 6,0 & - & 3,0 & - \\
\hline Tipo Bollo & 149 & 49 & & & & & & & \\
\hline Subt. Común & 144 & 97 & 1,6 & 0,2 & $1,0-2,4$ & 1,5 & 0,2 & 1,0 & 0,2 \\
\hline Subt. Grande & 5 & 3 & 2,4 & 0,5 & $1,6-3,3$ & 1,8 & 0,2 & 1,4 & 0,3 \\
\hline Tipo Humi & 12 & 4 & & & & & & & \\
\hline Subt. Común & 5 & 42 & 4,5 & 0,0 & $4,5-4,5$ & 2,3 & 0,2 & 2,2 & 0,1 \\
\hline Subt. Larga & 6 & 50 & - & - & - & 1,9 & 0,3 & 1,7 & 0,3 \\
\hline
\end{tabular}




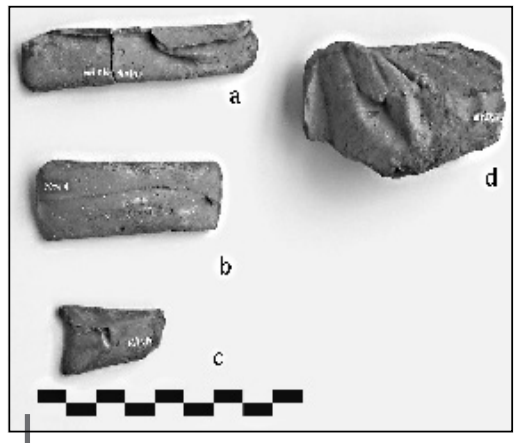

Figura 3 - Tipología formal de las empanadillas de Atacames. Subtipos: a) Tamal Largo, b) Tamal Común, c) Tamal Corto y d) Tamal Grande

Foto: M. Guinea
Las 20 empanadillas enteras pertenecen a los tres últimos subtipos. No es posible cuantificar cuántas empanadillas de la colección pertenecen a cada subtipo, ya que la mayor parte están partidas. Sin embargo, todas las calificadas como incompletas permiten obtener sus datos de ancho y grosor, observándose que estas medidas ( $2 \mathrm{~cm}$ de ancho por 1 de grosor) están muy estandarizadas en todos los tipos independientemente de su longitud (tabla 1), presentando una ligera tendencia a aumentar el grosor cuando lo hace el ancho. Como hemos dicho, solo hay seis ejemplares del tipo Tamal Grande (fig. 3d) y todos ellos son fragmentos. Si aplicamos a estos fragmentos los índices de proporcionalidad formal de los otros tipos, obtenemos para los seis la mismas cifras: $12 \mathrm{~cm}$ de largo, $6 \mathrm{~cm}$ de ancho y un grosor de $3 \mathrm{~cm}$. Por lo tanto, su tamaño original debió ser el doble de largo y tres veces más grueso y ancho que el Tamal Común (fig. $3 b)$. Estas empanadillas más grandes, que se asemejan al tamaño de un tamal normal, solo representan $1 \%$ en ambos yacimientos.

\section{2. Tipología formal de las empanadillas de Japoto}

Ya hemos dicho que las empanadillas de Japoto presentan una tipología formal más variada que las de Atacames (fig. 4, tabla 1) por lo que se han establecido tres tipos:

- Tipo Tamal, subtipos Grande, Común y Largo, 37 \% (fig. 4b).

- Tipo Bollo, subtipos Grande y Común, 49 \% (fig. 4c)

- Tipo Humita, subtipos Grande, Común y Largo, 4 \% (fig. 3a)

El tipo Tamal lo comparte con Atacames, aunque la manera de envolver la tierra con la hoja no es idéntica lo que produce una forma ligeramente diferente (figs. 3 y 4), en general más redondeada y con los extremos menos aplastados, no tenemos ningún ejemplar con su longitud completa, pero el fragmento más largo del subtipo Común alcanza los $6 \mathrm{~cm}$ y por su forma no debieron serlo mucho más. Sin embargo, como en el caso anterior, la mayor parte permite la medida de su ancho y su grosor. El primero coincide plenamente con los del yacimiento anterior en el caso del Tamal Común con una media 2,1 cm, siendo los de Japoto ligeramente más gruesos, $1,5 \mathrm{~cm}$ (tabla 1). Los Tamales Largos (1,7 cm de ancho) son un poco más estrechos, aunque la similitud

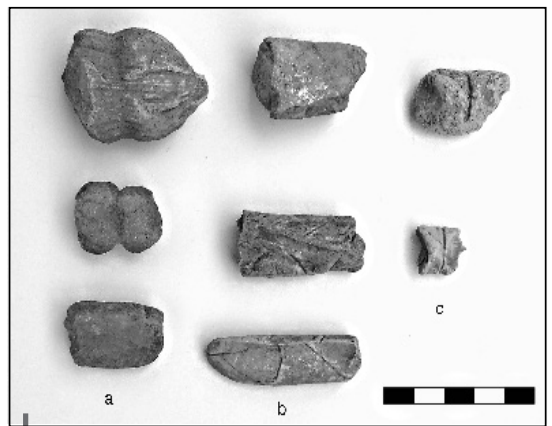

Figura 4 - Tipología formal de las empanadillas de Japoto. Tipos: a) Humita (de arriba abajo, Grande, Común y Larga) b) Tamal (Grande, Común y Largo) y c) Bollo (Grande y Común).

Foto: M.Guinea. formal es aún más evidente en este subtipo (figs. 3a y $4 \mathrm{~b}$ abajo). Si aplicamos a los escasos fragmentos del subtipo Tamal Grande los índices de proporcionalidad formal de los otros tipos, tal y como hicimos con los de Atacames obtenemos la mismas cifras: $12 \mathrm{~cm}$ de largo, $6 \mathrm{~cm}$ de ancho $\mathrm{y}$ un grosor de $3 \mathrm{~cm}$.

El tipo Bollo (fig. 4c) agrupa unas empanadillas pequeñas, casi cuadradas, también envueltas en hoja de bijao, pero en este caso el raquis de la hoja es perpendicular al lado más largo (quizás una necesidad técnica debido a su pequeño tamaño) y se aplasta en los extremos empujando hacia adentro. Son las más abundantes en el yacimiento y gran parte se han recuperado completas, con un tamaño igualmente altamente estandarizado con una media de 1,6 $\mathrm{cm}$ de largo por 1,5 de ancho y un grosor de 1,0, en el subtipo Común (fig. 4c abajo), aumentándose en un tercio estas cifras en el subtipo Grande (fig. 4c arriba). Podrían estar 
cumpliendo la función del subtipo Tamal Corto del yacimiento de Atacames (fig. 3c), que aquí no aparece, aunque son en general más pequeñas.

Las empanadillas de tipo Humita (fig. 4a) son las menos frecuentes. Los subtipos Grande y Común tienen una forma más compleja. Fueron envueltas en una hoja de choclo girada en sus extremos y atada en el centro, lo que produce al menos tres núcleos de tierra globulares, los dos de los extremos apuntados. Su tamaño es igual al de las anteriores, pero su aspecto es muy diferente. No hay ninguna entera. Las que hemos denominado con el fin de equiparar las nomenclaturas, Humita Largo (fig. 4a abajo), no debieron ser en realidad más largas, sino que debido a una manera diferente de envolverlas en la hoja de choclo y a la falta de la huella del atado, su forma final es rectangular.

Completa la colección un único ejemplar atípico, cilíndrico y sin huella de hoja y siete fragmentos tan deteriorados que no han podido ser asignados a ningún tipo.

\section{3. Las hojas impresas}

Hay una cierta variedad de hojas utilizadas como envoltorio para las tierras (fig. 5). Hasta el momento solo disponemos de un estudio botánico preliminar de las huellas que presentan las empanadillas de Atacames (figs. 1, 2 y 5c). Según éste, las huellas están producidas por fragmentos de limbo enrollados en el que se marcan el raquis central y los nervios. Sus características corresponden a hojas de grandes proporciones $\left(20-182 \mathrm{~cm}^{2}\right)$, propias de climas húmedos y calurosos, pertenecientes a las familias de las Palmáceas y Musáceas (Mingarro et al., 1981: 123-125). Creo que es posible una mayor aproximación y reconocer la hoja del bijao (Calathea sp. o Heliconia bihai $L$, ya que a ambas parece dársele el mismo nombre y utilidad) y muy probablemente la Achira (Canna edulis). En cualquier caso, no se están empleando hojas de un tipo especial, sino las que se usan de forma habitual para cocinar hasta nuestros días. Especialmente, en el caso del bijao, que parece una de las frecuentes, sus hojas pueden resistir el horneado, el asado a la brasa y la cocción prolongada. Para darle la flexibilidad necesaria para amoldarse sin romperse, antes de usarlas se mojan en agua caliente, o se pasan ligeramente por el fuego, después cuando la masa está cocinada se desprenden fácilmente, dejando su huella si la finura de la masa lo permite. A parte de su función de contenedor la hoja del bijao transmite un agradable sabor al alimento que se cuece en ella.

En Japoto aparentemente se utilizaron una menor variedad de hojas para envolver que en Atacames (fig. 2, figs. 4 y $5 a, d$ y b). Pero sus huellas, parecen ser también en la mayor parte las del bijao, aunque dejando un raquis central más marcado. Es posible aventurar que esta diferencia es debida a que los habitantes de Atacames ponían las tierras en el haz de la hoja (fig. 5c) y los de Japoto en el envés (fig. 5d). Aquí además tenemos ejemplos de otra hoja, la del choclo de maíz habitualmente usada para envolver y cocinar alimentos en la zona (fig. 5b). No sabemos qué significado puede tener el uso de diferentes hojas, pero los análisis mineralógicos no indican diferencias en la composición de las tierras.

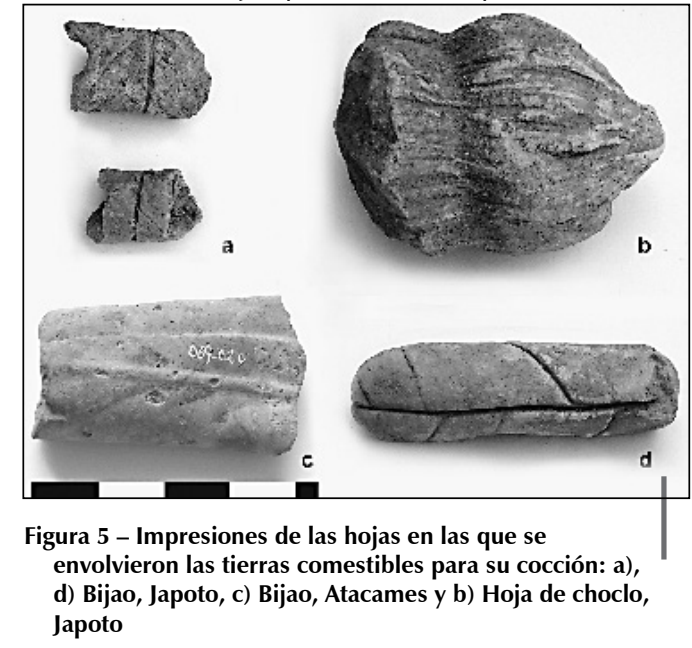

Foto M. Guinea 


\section{4. Análisis y composición mineralógica}

Al igual que en el caso del estudio botánico, contamos con unos primeros análisis de la composición de las empanadillas de Atacames (Mingarro et al., 1981). Se realizó el estudio petrográfico (Microscopía Óptica) y Difracción de rayos X (DX) de 16 ejemplares. Esta última técnica nos mostró una composición mineralógica constante cuyo componente más abundante era la calcita, en mucha menor cantidad plagiocasas y una pequeña proporción de micas abiertas (posiblemente illitas degradadas). En algunas muestras aparecieron otros componentes como la ankerita (carbonato de cálcio, magnésio y hierro también llamada dolomita ferruginosa) y la hematita (óxido férrico). El estudio petrográfico añadió a estos datos que la calcita se presentaba de forma dispersa, no cristalizada, y la presencia de cuarzos en forma de clastos angulosos y subangulosos.

En su resumen, los autores del citado artículo nos dicen que las empanadillas fueron elaboradas «a base de material fino, de naturaleza carbonática, modelados a mano (de ahí la orientación que se observa en algunos casos) y sometidos a una ligera cocción, nunca elevada ya que no llegaron a alterarse determinados componentes mineralógicos» (Mingarro et al., 1981: 120). Finalmente, con el fin de comprobar la selección deliberada de estas arcillas para fabricar las empanadillas, se realizaron análisis similares de una muestra de los objetos cerámicos del yacimiento dando como resultado que la composición de la pasta (arcilla) de las piezas cerámicas era uniforme y esencialmente diferente a la de las empanadillas (calcita) (Mingarro et al., 1981: 125).

Actualmente Nicole Platel 3 ha analizado dos ejemplares más aplicando las técnicas anteriores y añadiendo las ventajas de la Microscopía Electrónica de Barrido (MEB). En su informe Nicole Platel nos dice que en el corte de una de las piezas (069-019) se nota una tierra calcárea homogénea y rica en granos calcáreos blancos y agregados de color marrón-rojizo, ricos en óxidos de hierro, y escasas inclusiones de pequeños granos de cuarzo y feldespatos. La identificación, mediante MEB, de los elementos que componen la pasta se muestra en la tabla 2. La difracción (DX) confirma estos datos: aparecen fuertes picos de calcita y otros menores de cuarzo y feldespato. No pudiendo identificarse la geotita o la hematita debido a que el reparto de los oxi-hidróxidos es demasiado aleatorio y la cristalinidad es baja.

Tabla 2 - Elementos y compuestos químicos minerales presentes en las empanadillas de los yacimientos de Japoto y Atacames

Análisis: Nicole Platel

ATACAMES

\begin{tabular}{ccccccccccccc}
\hline & $\mathrm{Na}_{2} \mathbf{O}$ & $\mathbf{M g O}$ & $\mathrm{Al}_{2} \mathbf{O}_{3}$ & $\mathrm{SiO}_{2}$ & $\mathbf{P}_{2} \mathbf{O}_{5}$ & $\mathbf{S}$ & $\mathbf{C l}$ & $\mathbf{K} \mathbf{O}$ & $\mathbf{C a O}$ & $\mathrm{TiO}_{2}$ & $\mathbf{M n O}_{2}$ & $\mathrm{Fe}_{2} \mathbf{O}_{3}$ \\
$069-019$ & - & 1,90 & 7,40 & 26,80 & 0,90 & - & - & 1,30 & 18,70 & 0,40 & - & 42,25 \\
$069-021$ & 0,40 & 3,40 & 5,60 & 21,70 & 1,20 & - & - & 1,30 & 48,90 & - & - & 17,50
\end{tabular}

JAPOTO

\begin{tabular}{lcccccccccccc}
\hline & $\mathrm{Na}_{2} \mathbf{O}$ & $\mathbf{M g O}$ & $\mathrm{Al}_{2} \mathbf{O}_{3}$ & $\mathbf{S i O}_{2}$ & $\mathbf{P}_{2} \mathbf{O}_{5}$ & $\mathbf{S}$ & $\mathrm{Cl}$ & $\mathbf{K}_{2} \mathbf{O}$ & $\mathrm{CaO}$ & $\mathrm{TiO}_{2}$ & $\mathbf{M n O}_{2}$ & $\mathbf{F e}_{2} \mathbf{O}_{3}$ \\
J3-EM1 & 2,94 & 3,46 & 8,19 & 41,27 & 6,74 & 8,14 & 0,00 & 2,33 & 11,4 & 0,57 & 0,74 & 13,38 \\
J3-EM2 & 2,94 & 2,31 & 6,77 & 51,27 & 3,94 & 3,91 & 0,00 & 2,79 & 9,10 & 0,41 & 0,00 & 16,26 \\
J3-EM4 & 1,00 & 2,13 & 7,07 & 31,53 & 0,52 & 0,21 & 0,61 & 1,19 & 42,74 & 0,69 & 0,42 & 11,59
\end{tabular}

3 Los análisis se han realizado en el Centre de Recherche en Physique Appliquée à I'Archéologie (CRP2A) del CNRS, UMR 5060 de la universidad de Bordeaux 3 
En resumen, se trata de una tierra calcárea ligeramente cocida conteniendo pequeños granos calcáreos y abundantes pequeños agregados rojos-oxidados, cuya concentración puede alcanzar $54 \%$ de hematita, transformada en magnetita en el transcurso de la cocción.

La otra pieza analizada (069-021) presenta una composición similar, con pequeñas diferencias. Su textura es más homogénea, hojaldrada y microagrietada, lo que conforma una empanadilla frágil y formando escamas. Los análisis con el MEB (tabla 2) revelan una tierra calcárea menos ferruginosa que la anterior y con más calcita. Los granos blancos, más numerosos y más pequeños que en la empanadilla precedente, son también muy ricos en carbonatos de calcio (63\%). Los resultados de la difracción (DX) también difieren poco: mucha calcita (mejor cristalizada) y raras inclusiones de minerales de cuarzo y de una arcilla que puede identificarse como esméctica (montmorillonita).

Como vemos, aunque estos nuevos análisis son más detallados, sus resultados coinciden básicamente con los obtenidos en los estudios precedentes. Hay que añadir un dato interesante: las superficies de las empanadillas muestran numerosos pequeños poros de salida de gas a la superficie. Esto indica que cuando fueron sometidas a la ligera cocción $\left(200^{\circ}-400^{\circ}\right)$ que se deduce de la transformación de los materiales, estaban dentro de la hoja.

Para Japoto sólo tenemos los análisis realizados por Nicole Platel en cuatro de los ejemplares, que se presentan en detalle en la tabla 2.

La muestra J3-EM1 es un limo cuarzoso friable de color ocre-amarillento, con poca arcilla y algo de calcio, potasio, sodio y magnesio, con un contenido importante de hierro (Fe2O3). La J3-EM2 es también un limo cuarzoso pero más fino y calcítico acompañado de los mismos elementos minerales. Estos también se encuentran en la empanadilla J4B-EM4 que es un material calcítico menos friable, con una textura más arenosa debida a la presencia de granos de cuarzo y feldespatos (anortita). M1 y M4 presentan además unas concreciones blancas ricas en fósforo y calcio y unas manchas marrones en superficie que son impregnaciones ferromanganésicas.

Finalmente el análisis de la muestra JSA-EM3, una de los dos únicos ejemplares envueltos en hoja de maíz, muestra que es un material calcítico muy duro con algunas inclusiones de cuarzos y feldespatos. Debido a un proceso tafonómico diferencial (fue recuperada en una salinera cercana a los montículos), está fuertemente impregnada de halita $(\mathrm{NaCl})$.

Comparando los hallazgos de ambos yacimientos vemos que todos son materiales calcíticos con un contenido importante de hierro y otros minerales, generalmente acompañados de cuarzos y feldespatos y raras arcillas esmécticas. Las diferencias más significativas entre ambas colecciones se refieren a la tierra inicial, siendo mucho más limosas las tierras de Japoto, y al grado de transformación de los minerales que sugiere una cocción más elevada $\left(200-400^{\circ} \mathrm{C}\right)$ para las empanadillas de Atacames.

En un futuro es necesario efectuar un mayor número de análisis en ambas colecciones atendiendo a los diferentes tipos de pasta, ya que el examen visual, según su color y textura, nos permite distinguir al menos 12 tipos diferentes de tierras en Atacames (fig. 1), siendo menor la variación entre las de Japoto.

\section{LAS TIERRAS COMESTIBLES}

Ya hemos adelantado que la composición mineralógica de las empanadillas, su modo de preparación, envueltas en hojas y ligeramente cocidas, junto a su contexto de aparición esencialmente doméstico, nos han llevado a considerarlas tierras comestibles. Vamos a valorar esta hipótesis a la luz de los antecedentes arqueológicos y las posibles comparaciones etnográficas.

Desgraciadamente, la información arqueológica es escasa y poco precisa debido, como hemos dicho más arriba, a la dificultad de su reconocimiento en el terreno. La evidencia más temprana en el área andina de un posible consumo de tierras es la encontrada en unos coprolitos del sitio precerámico Huarmey (PV35-6) en la costa peruana, en fechas en torno a 2500 a.C. 
Estos contenían una cantidad de arena que no parecía accidental (Bonavia et al., 1993: 437), aunque se mantienen dudas sobre su significado. Dillehay et al. (1997: 50), en fechas aún más tempranas (5770-3000 a.C.) identificaron en el valle de Zaña unos hornos para producir cal a partir de piedras calcáreas. Propusieron, como el uso más probable del producto, su consumo junto a hojas de coca, si bien no descartan que también cumplieran la función de suplemento mineral en la dieta. Browman (2004: 134-135), en la introducción de un estudio de las tierras comestibles a la venta actualmente en el mercado de Oruro en Bolivia, habla de media docena de tierras comestibles (pasa, katawi, lejía, makaya, millu y sirsukena) encontradas en distintos contextos arqueológicos de las costas de Perú y Chile y de la cuenca del Titicaca, abarcando un periodo cronológico desde 510 a.C. hasta 1450 d.C. Lamentablemente para nuestros intereses, ya que la información es de difícil acceso, solo nos ofrece la composición mineralógica de las tierras y no su aspecto físico. Cuando es posible acceder a la información, como es el caso de las tumbas Nazcas excavadas por Kroeber \& Collier en Cantayo (1998: 70-71 y 259) los datos son tan decepcionantes como «terrón de yeso» y «terrón friable de arenisca marina». Recientemente Richard Cooke me ha mostrado amablemente unos 15 objetos no identificados procedentes de sus excavaciones en Cerro Juan Díaz en Panamá, que en mi opinión son artefactos similares a las empanadillas.

Algo más de suerte tenemos con las noticias de los cronistas. El jesuita Bernabé Cobo en su Historia del Nuevo Mundo nos da noticia de cuatro tipos diferentes de arcillas y tierras (pasa, chaco, millu y tacu) preparadas de diversos modos (salsas, polvos, cocimientos), que los indios del Perú comían con diversos fines curativos y detoxificantes e incluso como golosina para las mujeres (Cobo, 1964 [1653]: 115-116). Nos interesa especialmente su referencia a la forma de presentación del Tacu, ya que este tipo de presentación se ajusta al aspecto físico de las empanadillas

«la cual, en panes y bollos ${ }^{4}$ venden los indios en las plazas y se aprovechan della para curar cámaras de sangre» (Cobo, 1964 [1653]: 116).

Con la misma intención de curar estas diarreas sanguinolientas los indígenas de Picoaza, a seis horas de camino de Puerto Viejo, no lejos del yacimiento de Japoto, bebían en 1605 «los polvos de cierta tierra blanca quemada $\gg$. (Ponce, 1992: 46)

Ciento cincuenta años después el explorador alemán, Alejandro de Humboldt (1985 [1799]: 433-436), ampliamente citado cuando se habla de geofagia en América del Sur, nos relata en su Viaje a las Regiones Equinocciales del Nuevo Continente, la curiosidad que le produjo el desmesurado consumo de tierra de los indios otomacos a las orillas del Orinoco, entre las confluencias del Meta y el Apure. Durante los meses en que la subida del río hacía escasear la comida, para calmar el hambre estos indios comían 3/4 de libra de poya, bolas de una greda muy fina y grasienta, que conservaban amontonadas en sus casas. Esta arcilla era seleccionada, moldeada y «ligeramente endurecida al fuego» (Humboldt, 1985 [1799]: 435). En el momento de comerla la humedecían de nuevo. En la estación de sequía, en la que la pesca era abundante, el indio otomaco no consumía esas cantidades, sino que «raspa sus bolitas de poya y mezcla un poco de arcilla a sus alimentos» (Humboldt, 1985 [1799]: 436). Entre sus prolijas explicaciones resaltamos el raspado, ya que al menos seis de las empanadillas de Japoto presentan una de sus superficies raspada (fig. 6), y el hecho de que las endurecían al fuego, ya que coincide con la preparación de nuestros artefactos, que están también ligeramente cocidos. El autor citado nos da noticia de otros muchos lugares del mundo en los que igualmente se consumía tierra, entre otros en la isla de Java en la que comían por golosina una arcilla ferruginosa que «tuestan después de haberla enrollado en pequeños cuernos» (Humboldt, 1985 [1799]: 439). Hay que hacer notar que este tostado no es por gusto, aunque parece que le da mejor sabor, ya que las

4 En otro lugar del mismo texto (Cobo, 1964 [1653]: 11) el autor nos define «bollo» como una masa envuelta en hoja de plátano o maíz, de diversos tamaños y semejante a los tamales de la Nueva España. Este término es el que se emplea en la costa ecuatoriana en la actualidad.

5 Debemos esta inestimable información a la etnohistoriadora Chantal Caillavet. 


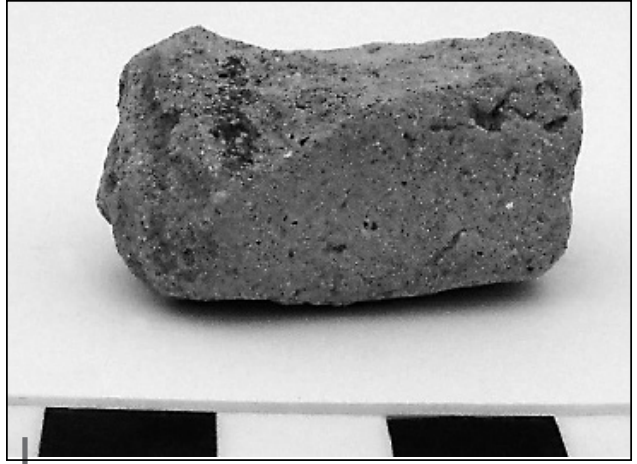

Figura 6 - Detalle de la superficie raspada de una empanadilla.

Japoto, J3PZC1-O4. Foto M.Guinea tierras deben de cocerse para reducir su posibilidad de contaminación bacteriana.

En su única referencia a Ecuador el explorador alemán nos dice que en las cercanías de Quito, todas las casas indígenas tenían grandes vasijas con «agua o leche de Llanka», arcilla fina diluida (Humboldt, 1985 [1799]: 440). Otros viajeros, estudiosos y antropólogos, en diferentes épocas y lugares nos dan noticias de costumbres similares (d'Orbigny, 1998 [1829]; Bates, 1848: 350; Mejia Xesspe, 1941; Weiss, 1953), que se han conservado hasta nuestros días si bien relegadas a los sectores más empobrecidos de la población dentro de las medicinas tradicionales o alternativas.

Recientemente, contamos con dos trabajos de gran utilidad a la hora de intentar una posible identificación del uso de las empanadillas, los de Girault (1984: 525-534) y Browman (2004). El primero nos da noticia de 25 minerales que son usados actualmente por la farmacopea Kallawaya, de los que la mayor parte son tierras para uso externo e interno. El segundo nos ofrece el resultado del análisis de 24 tipos de tierras comestibles a la venta en el mercado de Oruro en Bolivia.

Comparando nuestros análisis con los datos que aportan los autores anteriormente citados y especialmente con los de Browman (2004: 136-38), ya que son más precisos, encontramos que las empanadillas se asemejan en mayor medida a las tierras que incluye en los dos primeros grupos en los que se dividen las del mercado de Oruro: Grupo de los filosilicatos y Grupo de sodio y calcio. En el primero de los grupos está la llamada pasa (aymara) o chaco (quechua) que son esmectitas (silicatos de aluminio hidratado de K, Mg y Fe). Los autores citados coinciden en su uso para la adsorción de las fitotoxinas, como antihemorrágico y en dolores estomacales. Browman, hace notar que entre sus ventajas dietéticas está la de proveer de complementos minerales esenciales, pero esto parece una apreciación suya y no de los usuarios. La pasa se vende en polvo, en barras y como golosina (Cobo, 1964 [1653]: 115 y Browman, 2004: 136). Girault (1984: 526) cita un Recetario Anónimo del 1873 en el cual se indica que su acción se potencia si se mezcla con otra tierra, taku. Del segundo grupo las más similares son las calcitas, en concreto: katawi, hakemasa y taku. El katawi de Oruro es fundamentalmente cal o calcita con trazas de algún elemento arcilloso, que se prepara como salsa y se consume con quinoa o cañihua, y el de los Kallawayas (Girault, 1984: 532), estalactitas calcáreas, útiles en las hemorragias bucales. Cobo no la menciona. La hakemasa analizada por Browman es un carbonato de calcio, con magnesio y silvita. Girault (1984: 533) la identifica como toba caliza y Cobo tampoco la menciona. Coinciden en su uso como antihemorrágico, añadiendo el primero sus poderes curativos contra el susto (Browman, 2004: 137) y citando el segundo un manuscrito anónimo de 1680 que aporta su utilidad en casos de disentería (Girault, 1984: 533). Finalmente, el taku es una caolinita, con algo de esmectita, para Browman (2004: 138), una arcilla limonita para Girault (1984: 533) (cocida o no), y tierra amarilla rica en hierro similar al Bolo Arménico del Viejo Mundo6 para Cobo (1964 [1653]: 115). Los tres coinciden en que se vende como panes, bolas o bollos y, aunque aquí parece haber una mayor diversidad de opiniones, se usa para el mal de aire7, hemorragias, diarreas y parálisis. Otra notable coincidencia con nuestros hallazgos es la composición de las bolas de poya de los otomacos. Humboldt (1985 [1799]:

6 Arcilla rojiza procedente de Armenia y usada en medicina, en pintura y como aparejo en el arte de dorar.

7 Decaimiento, vómitos, diarrea y fiebre, al igual que dolores de cabeza. También calambres, artritis, dolor reumático, tos y resfrío. Parálisis. 
435) hace notar que estas no son esteatitas8 como parecía pensarse, si no que, por el contrario, tienen en su composición una mayor cantidad de sílice que de alúmina, junto a óxido de hierro y cal. Nuestras empanadillas tienen un casi cuatro veces más sílice que alúmina. Coinciden con esto las preferencias de las medicinas naturistas actuales que consideraran que las arcillas más interesantes desde el punto de vista terapéutico son las más ricas en sílice9.

Sin perder de vista que el tiempo transcurrido y los distintos procesos tafonómicos experimentados por cada una de las empanadillas deben tener su reflejo en el resultado de los análisis de su composición, si juntamos estos con su color y forma de presentación, quizás sea el taku10, o mejor aún, la mezcla de taku y pasa de la que habla el Recetario Anónimo de 1873 citado más arriba (Girault, 1984: 526), la identificación más probable de nuestras empanadillas, lo que nos permite plantear la hipótesis de un uso semejante al actual por los pueblos de costeros de Ecuador en el periodo anterior a la llegada de los españoles.

Quedaría por hacer una reflexión sobre la relegación del uso de estas tierras en la zona, lo que ha dificultado su identificación como tales. Estudios de etnomedicina en la provincia de Manabí muestran que la medicina tradicional de esta provincia se encuentra más relacionada con las costumbres españolas que con la tradición indígena (Sanhueza, 1980). En el caso de Esmeraldas el rápido sometimiento de la región a los esclavos africanos, cuyos descendientes ocupan actualmente la mayor parte, produjo igualmente un abandono de la prácticas medicinales de los antiguos indígenas. En cualquier caso, hubo una fuerte persecución de este uso de tierras comestibles en tiempos de la colonia en todo el continente americano. Por ejemplo, en el pueblo de Huehuetlan en 1625 comer tierra se castigaba con más de cien azotes y la pérdida de los derechos a tener algún cargo público durante cuatro años (Castello, 1986 : 104). Es probable que esta persecución fuera debida al carácter mágico religioso de la medicina indígena con independencia de la acción empírica de los principios activos de sus remedios. En este sentido, es interesante que algunos santuarios católicos de gran prestigio, tanto antigua como actualmente, estén levantados sobre terrenos con este tipo de tierras comestibles, generalmente relacionados con algún hecho milagroso. En ellos se ofrecen a los fieles tabletas con estas tierras benditas para curar sus enfermedades por la intervención divina11. Estas tabletas suelen tener impresa una imagen religiosa. Al menos en el mexicano Santuario de Nuestra Señora de San Juan de los Lagos en Jalisco, algunas de ellas tienen simplemente impresa la hoja en la que se cocieron, semejándose entonces, notablemente a las empanadillas (fig. 7).

\section{CONCLUSIÓN}

Todo lo anteriormente expuesto nos permite plantear la hipótesis de que los artefactos localizados en Atacames y Japoto, que estamos llamando empanadillas, son tierras comestibles del tipo del taku o la pasa, e incluso de la poya, cuyo consumo pervive desde tiempos prehispánicos en distintas regiones del continente americano. Su uso principal estaría relacionado con sus propiedades de adsorción de toxinas y protección de las mucosas del tracto intestinal ante

8 Filosilicatos de magnesio y hierro.

9 Entre otras propiedades, la sílice tiene la de ser un importante agente antitóxico.

10 Como hemos visto en el texto hay una cierta discrepancia entre la composición de las muestras de taku analizadas por Browman y la información etnográfica, que él mismo hace notar (Browman, 2004: 138). En nuestro caso, la composición de las empanadillas se asemeja más al taku de Girault y Cobo.

11 Un caso clarísimo es el del Santuario de Chimayo en Nuevo México, conocido como el Lourdes de América, levantado sobre las rojas tierras de las montañas de la Sangre de Cristo. La tierra bendita que mana de su pocito, entre otros usos, es preparada en infusión por los peregrinos para curar síntomas similares a los que cura el taku. Ejemplos semejantes son el Santuario de Nuestra Señora de San Juan de los Lagos de Jalisco y el Santuario de Señor del Santo Entierro de Carácuaro en México y el Santuario del Cristo Negro de Esquípulas en Guatemala, entre otros. 


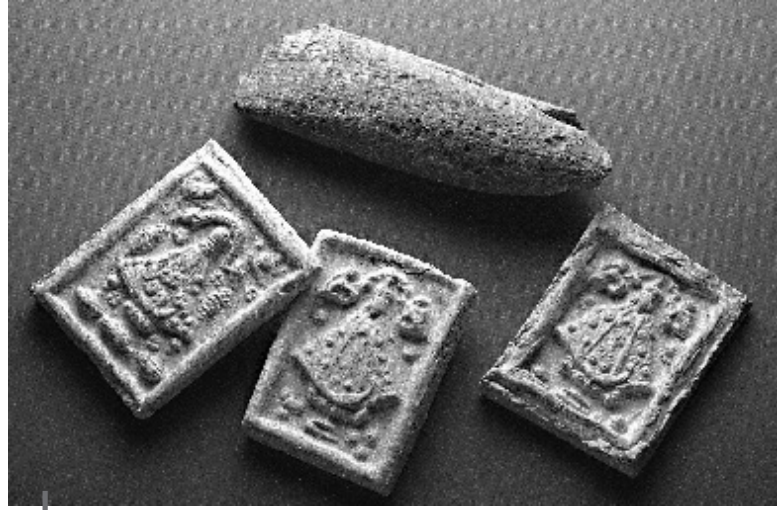

Figura 7 - Tabletas de tierra bendita del Santuario de Nuestra Señora de San Juan de los Lagos en Jalisco, México

Foto tomada de Castelló (1986: 105, fig. 54) estos tóxicos químicos, dentro de una dieta muy rica en alimentos con alto contenido en distintas fitotoxinas. Si bien la presencia en su composición de calcio, hierro y otros minerales necesarios para el buen funcionamiento del cuerpo humano también debió contribuir a otros aspectos de la salud de sus consumidores. Las empanadillas se cocieron o tostaron para impedir la proliferación bacteriana, y de paso mejorar su sabor, envueltas en hojas como cualquier otro tamal o bollo. El tamaño pequeño de la mayor parte parece indicar que su función no fue la de ser un sustituto alimenticio, como en el caso de los otomacos, si no que se consumiría como condimento, con fines medicinales e incluso como golosina.

\section{Agradecimientos}

Esta investigación ha sido parcialmente financiada por el Ministerio Español de Educación y Ciencia (TIN200508788-C04-04).

Agradecemos a Nicole Platel, José Ángel López y María Ángeles Barriuso su ayuda y comentarios en distintos momentos del desarrollo de esta investigación.

\section{Referencias citadas}

ALCINA FRANCH, J., 1979 - La Arqueología de Esmeraldas (Ecuador). Memorias de la Misión Arqueológica Española en el Ecuador, Vol. I, 165 p.; Madrid: Ministerio de Asuntos Exteriores.

BATES, H. W., 1984 [1848] - El naturalista por el Amazonas, Barcelona: Alertes.

BONAVIA, D., JOHNSON, L., REITZ, E., WING, E. \& WEIR G., 1993 - Un sitio Precerámico de Huarmey (PV35-6) antes de la introducción del maíz. Bulletin de l'Institut Français d'Études Andines, 22 (2): 409-442.

BOUCHARD, J.-F., 2004 - Proyecto Manabí Central. Informe de Actividad año 2004. Manuscrito presentado al Instituto Nacional del Patrimonio del Ecuador, Subdirección Regional de Guayaquil.

BOUCHARD, J.-F., 2005 - Proyecto Manabí, Costa central del Ecuador. Sitio de Japoto. Temporada 2005. Informe de Actividad. Manuscrito presentado al Instituto Nacional del Patrimonio del Ecuador, Subdirección Regional de Guayaquil.

BROWMAN, D. L., 2004 - Tierras comestibles de la Cuenca del Titicaca: Geofagia en la prehistoria boliviana. Estudios Atacameños, 28: 133-141.

COBO, B., 1964 [1653] - Historia del Nuevo Mundo (Edición de F. Mateos), T. I, 240 p.; Madrid: Biblioteca de Autores Españoles, Ediciones Atlas.

CASTELLÓ YTURBIDE, T., 1986 - Presencia de la comida prehispánica, 193 p.; México: Fomento Cultural BANAMEX

DANFORD, D. E., 1982 - Pica and Nutrition. Annual review of nutrition, 2: 303-322.

DILLEHAY, T., ROSSEN, J. \& NETHERLY P., 1997 - The Nanchoc Tradition: The Beginnings of Andean Civilization. American Scientist, Vol. 85: 46-55. 
DOMINY, N. J., DAVOUST, E. \& MIKENUS, M., 2004 - Adaptative function of soil consumption: an in vitro study modeling the human stomach and small intestine. The Journal of Experimental Biology, 207: 319-324.

D'ORBIGNY, A., 1998 [1829] - Viaje por América meridional; Buenos Aires: Emecé.

ESTRADA, E., 1957 - Prehistoria de Manabí, 82 p.; Guayaquil: Publicación del Museo Victor Emilio Estrada, $\mathrm{n}^{\circ} 3$.

ESTRADA, E., 1962 - Arqueología de Manabí Central, 205 p.; Guayaquil: Publicación del Museo Victor Emilio Estrada, $\mathrm{n}^{\circ} 7$.

GIRAULT, L., 1984 - Kallawaya. Guérisseurs itinérants des Andes, 668 p.; Paris: Éditions de I'ORSTOM, Collection Mémoires, $\mathrm{n}^{\circ} 107$.

GUINEA, M., 1984 - Patrones de Asentamiento en la arqueología de Esmeraldas (Ecuador). Memorias de la Misión Arqueológica Española en el Ecuador, Vol. 8, 243 p.; Madrid: Ministerio de Asuntos Exteriores.

GUINEA, M., 1988 - El desarrollo espacial del poblado de Atacames, Esmeraldas (Ecuador). Revista Española de Antropología Americana, 24: 93-111.

GUINEA, M., 1989 - Valoración de las evidencias de intercambio en la desembocadura del río Esmeraldas: el problema cronológico. In: Relaciones interculturales en el área ecuatorial del Pacífico durante la época precolombina (J.-F. Bouchard \& M. Guinea, eds.): 127-46; Oxford: B.A.R. International Series, 503.

GUINEA, M., 1993 - Diferentes mecanismos de articulación hombre-entorno en la costa norte del Ecuador: La desembocadura del Esmeraldas del principio de nuestra era al 1527. In: Primer Encuentro de Investigadores de la Costa Ecuatoriana en Europa (Alvarez et al., eds.): 47-67; Quito: Ediciones Abya-Yala.

HUMBOLDT, A., 1985 [1799] - Viaje a las Regiones Equinocciales del Nuevo Continente, 601 p.; Caracas: Monte Ávila Editores, T. 4 (Traducción de Lisandro Alvarado).

JONHS, T. \& DUQUETE, M., 1991 - Detoxificación and mineral suplementation as funcions of geophagy. American Journal of Clinical Nutrition, 53: 448-456.

KROEBER, A. L. \& COLLIER, D., 1998 - The archaeology and pottery of Nazca, Perú: Alfred L. Kroeber's 1926 expedition, 259 p.; Walnut Creek: Altamira Press.

LANZKOWSKY, P., 1959 - Investigation into aetiology and treament of pica. Archives of Disease in Childhood, 34: 140-148.

MEXIA XESSPE, M.T., 1941 - Contribución al estudio de la geofagia en el Perú. Revista 3, SepDic: 96-102.

MINGARRO, F., BARRIUSO, A., LÓPEZ DE AZCONA, C. \& ÁlVAREZ, C., 1981 - Estudio petrográfico de algunos artefactos arqueológicos de dudosa interpretación. Revista Española de Antropología Americana, Vol. XI: 113-130.

PONCE LEIVA, P. (ed.), 1994 - Relaciones Histórico-Geográficas de la Audiencia de Quito, siglos XVI- XIX, T. II (s. XVII-XIX); Quito: Marka/Abya-Yala.

SAMANO, J., 1884 [1526] - Relación de los primeros descubrimientos de Francisco Pizarro y Diego de Almagro, sacada del códice número CXX de la Biblioteca Imperial de Viena, Tomo V: 193- 201; Madrid: Colección de Documentos Inéditos para la Historia de España.

SIMON, S. L., 1998 - Soil ingestión by humans: A review of history, data, and etiology with application to risk assessement of radioactively contaminated soil. Health Physics, 74: 647-672.

SANHUEZA, R., 1980 - Etnomedicina en la provincia de Manabí. In: La medicina tradicional ecuatoriana (Argüello \& Sanhueza, eds):120-190; Quito: Ediciones del BCE-Abya YalaIOA. Colección Pendoneros, vol. 33.

WEISS, P., 1953 - Los Comedores Peruanos de Tierras. Datos históricos sociales y geográficos. Nombres de las tierras comestibles: Interpretación fisiológica de la geofagia y la pica. Perú Indígena, 5: 12-21.

WILSON, M. J., 2004 - Clay mineralogical and related characteristics of geophagic materials. Journal of Chemical Ecology, 29: 1525-1547. 